ERRATUM P 23

\title{
Erratum: Prokaryotic transcription regulation by the nascent RNA elements
}

Seungha Hwang ${ }^{\dagger}$, Jimin Lee ${ }^{\dagger}$ and Jin Young Kang*

Department of Chemistry, Korea Advanced Institute of Science and Technology, Daejeon 34141, Republic of Korea ${ }^{*}$ Correspondence: jykang59@kaist.ac.kr

${ }^{\dagger}$ These authors contributed equally to this work.

Biodesign 2020;8:33-40.

https://doi.org/10.34184/kssb.2020.8.2.33

This erratum is being published to add ACKNOWLEDGEMENTS:

\section{ACKNOWLEDGEMENTS}

This research was supported by Basic Science Research Program through the National Research Foundation of Korea (NRF) funded by the Ministry of Education (2019R1A6A1A10073887). 